\title{
How emergency managers (mis?)interpret forecasts
}

\section{Kris Wernstedt, Patrick S. Roberts, Joseph Arvai, and Kelly Redmond ${ }^{1}$}

Emergency managers who work on floods and other weather-related hazards constitute critical frontline responders to disasters. Yet, while these professionals operate in a realm rife with uncertainty related to forecasts and other unknowns, the influence of uncertainty on their decisionmaking is poorly understood. Consequently, a national-level survey of county emergency managers in the United States was administered to examine how they interpret forecast information, using hypothetical climate, flood, and weather scenarios to simulate their responses to uncertain information. The study revealed that even emergency managers with substantial experience take decision shortcuts and make biased choices, just as do members of the general population. Their choices vary depending on such features as the format in which probabilistic forecasts are presented and whether outcomes are represented as gains or losses. In sum, forecast producers who consider these decision processes when developing and communicating forecasts could help to improve flood preparation and potentially reduce disaster losses.

Keywords: cognitive, decision-making, emergency management, risk, uncertainty

\section{Introduction}

For decades, meteorologists, psychologists, and others in the disaster community have conducted studies on challenges in communicating weather-related forecasts (Scoggins and Vaughan, I97I; Murphy et al., I980; Sink, I995; Nicholls, I999; Adams and Golden, 2000; Gigerenzer et al., 2005; Morss, Demuth, and Lazo, 2008; Joslyn, Nadav-Greenberg, and Nichols, 2009; Joslyn and Nichols, 2009; Joslyn, Savelli, and Nadav-Greenberg, 20II; LeClerc, 20I4; Morss et al., 20I5). These analyses have documented that information processing and decision shortcuts often lead forecast users within the general public to behave 'irrationally' or predictably incorrectly when faced with uncertain information. For instance, users may interpret probabilities differently than is the intention of providers, or anchor themselves to initial estimates and not adjust when new information becomes available. More broadly, the public's use of available forecast information to reduce weather-related disaster damage appears to depend critically on risk perception and communication, as highlighted by recent work on forecast and weather warning interpretation of, and responses to, floods (Demeritt and Nobert, 20I4; Silver, 20I5), hurricanes (Lazo et al., 20I5; Morss and Demuth, 20I6), and tornadoes (Miller, Adame, and Moore, 20I3; Stokoe, 2016).

The research reported here extends these evaluations by focusing on county emergency managers (EMs) in the United States, local-level professionals who apply management, planning, science, and technology to deal with flooding that can cause property 
damage, disrupt community life, and kill or injure people (Hoetmer, I99I, p. xvii). Do these first-responder experts face the same kind of decision constraints revealed in other assessments of forecast use in weather-related disasters, almost all of which have examined the general public (see, for example, Joslyn, Nadav-Greenberg, and Nichols 2009; Lazo, Morss, and Demuth, 2009; Joslyn and Savelli, 2010; Joslyn and LeClerc, 20I2; LeClerc and Joslyn, 20I5; Zabini et al., 20I5). Only a small number have concentrated on professionals involved with forecasts, such as the forecasters themselves (Demeritt et al., 2007, 2013; Pappenberger et al., 2013), experts interested in using flood visualisation tools (Frick and Hegg, 20II), and emergency service providers (Kox, Gerhold, and Ulbrich, 2015). In addition, do local emergency managers face the same difficulties in interpreting seasonal forecasts with lead times of months - where the pressures for quick decision-making are weaker-as Coventry and Dalgleish (2015) found for lay people?

Certainly, advances in science and technology and the era of big data suggest greater potential for utilising short- and long-term forecast information to decrease flood-related losses. Improvements in remotely-sensed data collection and application and the development of physically-based distributed hydrological models have significantly enhanced six-hour flash-flood forecasting, for instance (Hapuarachchi, Wang, and Pagano, 20II), and numerical bias-corrected, ensemble forecasts now notably outperform experienced human forecasters (Novak et al., 20I4). On the longer time horizon, the Climate Prediction Center, the International Research Institute for Climate Prediction, and other organisations have taken advantage of research conducted over the past few decades and developed a number of long-lead forecasts (seasonal to I 2 months) that offer modest to moderate skill in some regions to predict the impacts on the ground (Barnston et al., I994; Dutton, 2002; Livezey and Timofeyeva, 2008; O'Lenic et al., 2008). Furthermore, researchers have documented numerous cases of innovative use of seasonal climate information in particular instances (Pielke, Jnr. and Pielke, Snr., I997; Changnon, I999; Pielke, Jnr. and Landsea, I999; Pulwarty and Melis, 200I; Hartmann et al., 2002; Wernstedt and Hersh, 2004).

Overall, however, seasonal forecasts have a mixed track record of actual sustained use by decision-makers on the ground (see, for example, Millner and Washington, 2OII). The evidence suggests that the application of long- and short-term flood and streamflow forecasts to reduce disaster losses needs to surmount systematic challenges. Sorensen and Mileti (1987) underlined decades ago that numerous factors can bedevil organisational decision-making and constrain the effectiveness of forecasts and other warnings in hazard contexts, including difficulties in recognising and interpreting indicators associated with threatening events and distinguishing relevant from irrelevant information, and concerns about taking action that produces adverse consequences for the public or a loss of personal reputation. More specific to flooding, Pagano et al. (20I4) trace a litany of factors pertaining to deficient data availability and quality, model limitations, insufficient attention to user needs, and socio-cultural institutional constraints that inhibit operational river forecasting. 
Consistent with these difficulties, Werner, Averyt, and Owen (20I3) draw on a series of workshops to demonstrate the limited use of probabilistic forecast information in water resource management scenarios involving forecast providers, water managers, and others interested in learning more about forecast methods. Our own survey of 48 EMs in Oregon, US, identified only two who used seasonal climate forecasts to help them decide to take action before a flood season (Roberts and Wernstedt, 20I6), despite a strong connection between seasonal climate events and flooding in the region (Wernstedt and Hersh, 2002). Moreover, while not focused on probabilistic information per se, the study by Peerbolte and Collins (20I3) of emergency managers' critical thinking skills — which they measured by applying a validated critical thinking measurement tool used in other parts of the country to a sample of local EMs in Virginia, US - suggests that EMs may have less ability to assume and manage risk as compared to the average of other peer-level managers without emergency management responsibilities.

This paper investigates one of the barriers noted in the other investigations: the cognitive challenges that uncertain information may pose to short- and longer-term forecast use by EMs. Uncertainty, here, means information with stochastic properties or probabilities of outcomes, rather than information that is simply 'unknown'. The work draws on the results of our recent nationwide survey of 23 I county-level EMs engaged in flood planning.

\section{Decision-making under the condition of uncertainty}

Barriers to more ubiquitous forecast use exist partly because local EMs must make decisions in a world rife with uncertainty. The psychology of decision-making under the condition of uncertainty suggests that unaided or ad hoc judgements frequently fail to yield informed, thoughtful, and sustainable choices and instead may introduce systematic biases into decision-making (Gregory et al., 20I2). These biases often follow from the use of heuristics or rules of thumb that people employ in assessing probabilities, which may stand them in good stead in situations that are familiar, but can be problematic in unfamiliar contexts. For example, prospect theory (Kahneman and Tversky, I979) suggests that individuals evaluate gains and losses differently and look at the values of these relative to the status quo, rather than select an alternative that leaves them the best off. Potential losses regularly loom larger in a decision calculus than seemingly equivalent gains, so the loss to an individual from inadvertently having USD Ioo fall out of a pocket while jogging in the park may represent a greater change in value (a loss) than does inadvertently finding USD Ioo while out for a run (a gain). More generally, individuals often make choices differently depending on factors external or irrelevant to the decision at hand, thereby violating a central tenet of rational choice theory.

Such biases are compounded by shortfalls in numeracy skills, that is, the ability to apply basic probability and numeric concepts to decision-making. For instance, those 
with more limited numeracy skills are more likely to view a bad outcome represented as occurring in Io per cent of cases differently than a bad outcome represented as occurring in Io out of Ioo cases, even though the two are numerically equivalent. Such shortfalls can exacerbate problems particularly in emotionally charged situations, compromising the capability to make good decisions with probabilistic information on weather forecasts and in other circumstances (Peters et al., 2006; Joslyn and Nichols, 2009). While some evidence suggests that most individuals generally understand uncertainty better when it is presented as a frequency rather than as a probability (Gigerenzer and Hoffrage, I995), including in some seasonal climate forecasting settings (Coventry and Dalgleish, 20I5), the Joslyn and Nichols (2009) study of weather (wind speed) forecasts shows the opposite. Moreover, understanding of the psychological processes undergirding numeracy challenges remains unsettled (Gigerenzer, I994; Slovic, Monahan, and MacGregor, 2000; Reyna and Brainerd, 2008).

In addition, the possible presence of 'attribution bias' means that different individuals in the chain of actors that turn a forecast into an action on the ground may anticipate, evaluate, or explain the motivations and actions of others in using forecasts differently than their own. This term reflects most generally a tendency for individuals to overemphasise the role of personality in explaining the behaviour of others, rather than the situational context of the behaviour, and to do the reverse for one's own behaviour. This can lead to a number of observed biases in group decision-making, such as the development of false consensus, and can exacerbate self-serving biases in which individuals may remain immune to constructive negative feedback.

\section{Survey of emergency managers}

Nichols (1999) summarised these and other biases as they relate to the climate forecast community nearly 20 years ago, but, with a few recent exceptions (see, for example, Demeritt et al., 20I3; Pappenberger et al., 20I3; Hoss and Fischbeck, 20I5; Morss et al., 20I5), most of the work on decision-making under forecast uncertainty related to risk, heuristic biases, and framing has assessed decision-making and risk perceptions among the general public, rather than among professionals who make decisions in work environments. To probe the latter, investigators typically have relied on controlled laboratory experiments in which university students take on the role of decision-makers acting in their professional capacity (see, for example, Joslyn and LeClerc, 2012). Older studies of actual weather forecasters by Murphy and Winkler (1977) and Stewart, Roebber, and Bosart (1997), though, indicate that, when compared to the general public, weather experts who regularly work with uncertain forecasts in professional settings have greater numeracy skills and a better ability to work with probabilities when tested in experimental situations. Hoss and Fishbeck (2015, p. 95) even suggest that 'most EMs have found ways to cope with forecast uncertainty and do not perceive it to be a major problem'. 
Does this mean that emergency managers are immune to decision heuristics and biases? Or do many face the same challenges as the general public in interpreting uncertain information, even as they encounter it more routinely during disaster preparation? Unfortunately, there is a lack of naturalistic decision-making studies (Klein, Orasanu, and Calderwood, I993) of EMs in the field to understand how they process uncertain information in real life. However, foreshadowing the conclusions of this study, the survey-based decision experiments in controlled settings with EMs in the US show that, in fact, they do confront similar challenges.

The survey questionnaire comprises 44 closed-ended questions, some of which relate to factual background information, such as the age, experience, and gender, of respondents, whereas others pertain to the hypothetical emergency management scenarios involving climate and flood forecasting uncertainty central to our experiments. During the latter, emergency manager subjects were asked to choose from among different actions in response to a hypothetical scenario. For each question involving a hypothetical scenario, respondents were randomly assigned to one of four subgroups, with each subgroup receiving a different hypothetical situation, or treatment, in the language of survey design (see below).

Prior to circulating the final questionnaire, a prototype version of the survey was pre-tested with students to solicit opinions on the design. Based on this feedback, adjustments were made to the visual presentation of the questions and the text was shortened. Next, a pilot test was performed with individuals in the emergency management profession not already identified in the sampling frame. Responses to this pilot led to several questions being made more succinct. After a small pre-test, the online survey was administered to the final sampling frame: I,350 county-level EMs in the US selected from a larger population of emergency managers with identifiable and valid email addresses acquired from public websites. Owing to concerns about lower response rates from rural counties due to more limited staff resources, this frame was stratified by rural and non-rural locations-delineated by using the federal Office of Management and Budget's designation of core and outside-core counties (United States Office of Management and Budget, 2010) — and oversampled in rural locations by splitting the frame equally into rural and non-rural locations (rather than constructing it to reflect the minority proportion of counties that are rural). In addition, the overall size of the sampling frame was set so as to satisfy the need for a minimum of 200 responses (based on power calculations) and an assumed response rate of I5 per cent (based on the pre-test). The survey was circulated using email invitations and there were two rounds of follow-up with non-respondents.

The 23I respondents represent a response rate of I7.I per cent, exceeding expectations set by the pre-test and the 9-I3 per cent level that the Federal Emergency Management Agency achieved in its 20IO-I2 annual survey of public officials on flood risk. The sample appears generally representative of the EM population. Table I presents a range of demographic and professional characteristics of the sample, as compared to those from a survey of more than I,00o EMs conducted recently by Weaver et al. (2013). The group matches the latter sample with respect to gender 
Table 1. Summary measures $(\mathrm{N}=231)$

\begin{tabular}{|l|l|l|}
\hline Variable & $\begin{array}{l}\text { Percentage of } \\
\text { study sample }\end{array}$ & $\begin{array}{l}\text { Percentage of sample in } \\
\text { Weaver et al. (2013) }\end{array}$ \\
\hline Male & 80.1 & 80.9 \\
\hline 45 years and older* & 86.2 & 71.0 \\
\hline 10 or more years of work experience & 63.2 & 71.2 \\
\hline Completed graduate or professional degree & 19.0 & 23.4 \\
\hline Work mostly in rural areas & 45.8 & 46.4 \\
\hline Flooding has occurred within the past 10 years & 78.8 & 67.1 \\
\hline
\end{tabular}

Note: * 46 years and older in the Weaver et al. (2013) survey.

Source: authors.

(overwhelmingly male) and closely resembles it in relation to other dimensions; that is, the EMs in this study sample are similar to the group in Weaver et al. (2013), but they are slightly older, less experienced, and not as likely to hold a graduate or professional degree, as well as having experienced floods more recently. The respondents in the current survey also appear comparable to groups of EMs assessed by Peerbolte and Collins (2013) and Jensen and Youngs (2015), who report samples similarly dominated by older, educated, experienced males. As for the community setting, the proportion of respondents in this study who come from rural areas was similar to that in Weaver et al. (2OI3): 46 per cent. This slightly exceeds the proportion of the more than 3,000 counties in the US that are situated in rural areas: 4I per cent. The respondents come from 29 states, with Connecticut having the largest single share (I I per cent). Each of the four US census regions (Northeast, Midwest, South, and West) provides at least 30 respondents, but there is overrepresentation of the Midwest (53 per cent of respondents versus 34 per cent of counties) and underrepresentation in the South (I 4 versus 45 per cent). Weaver et al. (2013) have a similar underrepresentation of EMs from the South, although it is less sharp (33 versus 45 per cent).

This paper focuses on four of the decision scenarios presented to EMs-one representing the numeracy problem and three pertaining to decision preferences with gains and losses. In each scenario, the survey software randomly assigned the EMs into four groups, with all members of each group facing the same treatment (same presentation of uncertainty) and treatments differing across groups. While this does not permit an examination of how a particular EM responds to different presentations of uncertainty in any one scenario (it is not a paired design), it does allow for a comparison of how groups of randomly selected EMs respond to different presentations of uncertainty. Moreover, the survey software randomly resorted respondents at the start of each new scenario to vary the composition of the groups. For instance, 60 EMs belong to group $\mathrm{C}$ in the first scenario and 58 belong to group $\mathrm{C}$ in the second scenario, but only io of these belong to both groups. ${ }^{2}$ 


\section{Scenario I: numeracy and emergency managers}

Each of the EMs who responded to the survey faced one of four possible versions of a hypothetical scenario about a long-term seasonal climate forecast predicting a destructive flood. The versions presented the likelihood of losses as low in two cases and high in two cases, but phrased it in different ways (I out of every Io or a O.I probability for the two low likelihood cases, and 9 out of every Io or a 0.9 probability for the two high likelihood cases). Each EM was asked to imagine receiving a long-term forecast predicting weather events for the next three months that suggests a destructive flood might occur in their county sometime during that time frame. Here, a destructive flood means that a large number of the I,00o homes in a vulnerable community in their county could be severely damaged or destroyed.

\section{Figure 1. Hypothetical situations for the assessment of numeracy}

A. Assume a vulnerable community in your county contains 1,000 homes, and the forecast predicts that 1 out of every 10 homes could be severely damaged or destroyed if action to protect the community isn't taken right now.

B. Assume a vulnerable community in your county contains 1,000 homes, and the forecast predicts that there is a 0.1 probability that homes could be severely damaged or destroyed if action to protect the community isn't taken right now.

C. Assume a vulnerable community in your county contains 1,000 homes, and the forecast predicts that 9 out of every 10 homes could be severely damaged or destroyed if action to protect the community isn't taken right now.

D. Assume a vulnerable community in your county contains 1,000 homes, and the forecast predicts that there is a 0.9 probability that homes could be severely damaged or destroyed if action to protect the community isn't taken right now.

Question 1: Of course, avoiding all losses is preferable to incurring some loss. But, assuming this prediction is accurate, how acceptable to you is this probability of loss if action isn't taken?

Not at all acceptable

Somewhat acceptable

Very acceptable

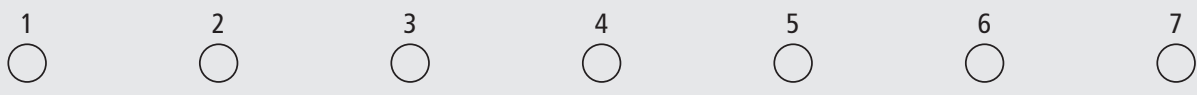

Question 2: Assuming the final decision falls to you, how likely would you be to activate a costly emergency management plan right now that is intended to protect all of the homes in this community in case the destructive flood occurs?

Not at all likely Somewhat likely Very likely
1
$\stackrel{2}{0}$
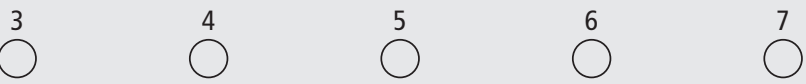

Notes: each respondent sees one of the four hypothetical situations labelled A-D and then answers questions 1 and 2 . The first two hypothetical situations, $A$ and $B$, are numerically equivalent to each other but express uncertainty in different ways. Similarly, the last two hypothetical situations, $C$ and $D$, are numerically equivalent to each other, but express uncertainty in different ways.

Source: authors. 
In each version of the scenario, EMs were questioned about the acceptability of the losses and the likelihood that they would activate a costly emergency management plan when confronted with the prospect of the loss (see Figure I). Possible responses spanned a seven-point scale ranging from one ('not at all acceptable') to seven ('very acceptable'), with four indicating 'somewhat acceptable'.

The results in Table 2 reveal that the EMs did not respond the same to the different ways in which we presented long-term flood forecasts with numerically equivalent probabilities. Section (a) in Table 2 shows the results of the first question about the acceptability of flood losses in a low likelihood situation. More than 30 per cent of EMs who read the 'I out of Io' uncertainty language indicated that the losses would be not at all acceptable (an acceptability rating of I), but less than Is per cent of EMs who read the 'O.I probability' language did the same. Nearly 20 per cent of each of the two groups indicated that this probability of loss was 'somewhat acceptable' (an acceptability rating of four), but a much higher proportion of EMs who read the 'O.I probability' language rated the scenario as more acceptable than did the EMs who read the 'I out of Io' language (that is, a much higher percentage selected an acceptability rating of five or more).

The differences between the two groups are significantly different statistically at the 0.05 level, using Somers' D, a non-parametric test (Newson, 2002) of association between discrete variables in this case (one variable representing binary categories of treatments and the other representing Likert-scaled, ordinal responses). Values of Somers' D range from -I.O (perfect inverse association) to $+_{\text {I.o }}$ (perfect positive association), with 0.0 indicating no association. The Somers' D value of 0.23 in this scenario means that randomly selected EMs reading the 'O.I' language are 23 per cent more likely to rate the scenario as more acceptable than randomly selected EMs reading the 'I out of Io' language.

Table 2. Acceptability of losses under different phrasing to describe flood likelihood*

\begin{tabular}{|l|l|l|l|l|}
\multirow{2}{*}{ Acceptability } & \multicolumn{2}{|c|}{10 per cent flood likelihood } & \multicolumn{2}{c|}{90 per cent flood likelihood } \\
\cline { 2 - 5 } & $\begin{array}{l}\text { (i) } 1 \text { out of } 10 \\
\text { probability language }\end{array}$ & $\begin{array}{l}\text { (ii) } 0.1 \text { probability } \\
\text { language }\end{array}$ & $\begin{array}{l}\text { (iii) } 9 \text { out of } 10 \\
\text { probability language }\end{array}$ & $\begin{array}{l}\text { (iv) } 0.9 \text { probability } \\
\text { language }\end{array}$ \\
\hline 1 & 32 & 13 & 41 & 21 \\
\hline 2 & 20 & 19 & 22 & 15 \\
\hline 3 & 10 & 17 & 5 & 21 \\
\hline 4 & 18 & 17 & 10 & 17 \\
\hline 6 & 10 & 21 & 7 & 10 \\
\hline 7 & 5 & 7 & 5 & 12 \\
\hline
\end{tabular}

Notes: * Cell entries reflect the percentage of the responses of a group; columns sum 100 per cent. Source: authors. 
Section (b) of Table 2 shows the analogous results for a forecast probability of 90 per cent. Sixty EMs were provided with the same general background of a vulnerable community with I, ooo homes, and then presented with a forecast probability that 9 out of every Io homes could be severely damaged or destroyed if action to protect the community was not taken right now. Another 58 EMs were presented with a forecast of a 0.9 probability that homes could be severely damaged or destroyed if action to protect the community was not taken right now. These two expressions equate to an expected damage of 900 homes (90 per cent of $\mathrm{I}, 000$ ). Once again, a much higher percentage of EMs who read the ' 9 out of Io' language indicated that such losses would be 'not at all acceptable' (an acceptability rating of one) than did those who read the '0.9 probability' language. This difference also is significantly different at the 0.05 level using the Somers' D test. The same Somers' D value of 0.23 means that EMs who read the '0.9' language in the context of the higher forecast probability are also 23 per cent more likely to rate the scenario as more acceptable than the EMs receiving that higher forecast probability who read the ' 9 out of Io' language; that is, the higher acceptability of losses associated with the 'O.I' language persists across different levels of uncertainty.

Table 3 presents the responses for an identical situation - a vulnerable community with I,ooo homes and with the same probabilities and ways of presenting uncertainty - but addresses the likelihood that an EM would activate a costly emergency management plan to protect homes in the community (see question phrasing in Figure I). Responses range from one ('not at all likely') to seven ('very likely'), with four indicating 'somewhat likely'. The patterns of responses between the two ways of presenting uncertainty deviate sharply for the ro per cent forecast likelihood. Section (a) in Table 3 shows that a much higher percentage of EMs presented with

Table 3. The likelihood of activating an emergency plan when different phrasing is used to describe the risk of flooding*

\begin{tabular}{|l|l|l|l|l|}
\multirow{2}{*}{$\begin{array}{l}\text { Likelihood of } \\
\text { activating } \\
\text { plan }\end{array}$} & \multicolumn{2}{|c|}{10 per cent flood likelihood } & \multicolumn{2}{c|}{90 per cent flood likelihood } \\
\cline { 2 - 5 } & $\begin{array}{l}\text { (i) } 1 \text { out of } 10 \\
\text { probability language }\end{array}$ & $\begin{array}{l}\text { (ii) } 0.1 \text { probability } \\
\text { language }\end{array}$ & $\begin{array}{l}\text { (iii) } 9 \text { out of } 10 \\
\text { probability language }\end{array}$ & $\begin{array}{l}\text { (iv) } 0.9 \text { probability } \\
\text { language }\end{array}$ \\
\hline 1 & 0 & 6 & 0 & 2 \\
\hline 2 & 2 & 23 & 0 & 9 \\
\hline 3 & 12 & 13 & 8 & 10 \\
\hline 4 & 18 & 19 & 23 & 26 \\
\hline 5 & 28 & 11 & 15 & 15 \\
\hline 6 & 20 & 19 & 34 & 21 \\
\hline 7 & 20 & 9 & 20 & 17 \\
\hline
\end{tabular}

Notes: * Cell entries reflect the percentage of the responses of a group; columns sum 100 per cent. Source: authors. 
the 'O.I probability' language are not as likely to activate an emergency management plan in response to the forecast as those presented with the 'I out of IO' language. Conversely, a much higher percentage of those who received the 'I out of Io' phrasing expressed a high likelihood of activating the plan. This is statistically different at the o.or level of significance. Here the Somers' D value of -0.35 indicates that those who read the 'O.I' language are 35 per cent less likely to take action than those who read the 'I out of Io' language. The differences appear less stark with a forecast probability of 90 per cent in section (b) of Table 3-as indicated by a Somers' D value closer to zero - and are significantly different only at the o. I level. We cannot explain this difference to our satisfaction, but it is possible that such a high likelihood forecast is so outside of emergency managers' experience as to be unrealistic or, alternatively, that it poses such a threat that the difference in the forecast language gets overshadowed.

These results suggest that for both low and high likelihood long-range flood forecasts, numeracy challenges influence the acceptability of losses and management responses to forecasts. Joslyn and Nichols (2009) reveal a similar phenomenon in experiments on wind speed forecasts that used different ways of presenting uncertainty, but unlike their study, we cannot say that expressing a forecast probability as a ratio or frequency to an EM yields a better decision or outcome than presenting it as a proportion, or vice versa. Rather, the first scenario shows that EMs respond to numerically equivalent forecasts expressed in different ways.

Recent work suggests that the format of risk information in flood forecasts influences the perceived usefulness of the information in decision-making, with quantitative (probabilistic) and semi-quantitative (ranking) presentations judged as superior to qualitative approaches (Lin et al., 20I7). However, the results of the Scenario I exercise point to the more basic problem identified by Joslyn and Nichols (2009), namely that limitations in the ability to process numerical information can lead to different decisions. In this study, it may be that EMs judge the likelihoods of losses expressed as O.I as less threatening than those expressed as I in Io because they anchor to the 'o', making the loss appear less possible. Regardless of the explanation, the numeracy limitation amplifies the previously identified need for forecasts and loss estimates to be set out in a variety of formats. In short, producers of information should not assume that one format will correctly translate the facts of the situation, since different expressions of the same expected utility produced different assessments among the respondents.

\section{Scenario II: prospect theory and emergency managers}

The second scenario in the survey questionnaire tests the applicability of prospect theory in the decision science literature to emergency management of floods; that is, it assesses whether EMs would take the same action when a problem is framed in terms of losses as when it is framed in terms of gains. In this case, the EMs were again divided into four groups, with each group seeing one of four versions of a hypothetical flood that differ in the way in which uncertain damage is presented 
(framed as a 'gain' of saving 25 homes from being destroyed out of Ioo homes versus framed as a 'loss' of losing 75 out of Ioo homes) and in the extent of damage associated with the flood (saving/losing $25 / 75$ out of Ioo homes versus saving/losing I $25 / 375$ out of 500 homes).

Each pair of versions poses the same trade-off to EMs. In the 'gain' framing version of the Ioo homes problem, the EM can choose either a sure outcome of saving 25 per cent of the homes or a gamble with a 25 per cent likelihood of saving all of the homes and a 75 per cent likelihood of saving none of the homes. In the 'loss' framing version of the Ioo homes problem, the EM can choose either a sure outcome of losing 75 per cent of the homes or a gamble with a 75 per cent likelihood of losing all of the homes and a 25 per cent likelihood of losing none of the homes. The expected value for versions with the same number of homes are identical (25 homes remain intact in both Ioo-home versions and 125 homes remain intact in both 500-home versions).

Table 4 shows the results of the 'gain' and 'loss' framing for both the Ioo- and 500home cases. The rows in the table represent changes in the framing of the choice, with the light grey-shaded rows representing a 'gain' frame (rows one and three for the Ioo- and 500-home situation, respectively), and the darker grey-shaded rows representing a 'loss' frame (rows two and four for the Ioo- and 500-home situation, respectively). Numbers in each row of the table sum Ioo; that is, they represent the percentage of respondents seeing that particular frame who chose a more risk-averse

\section{Table 4. Gain and loss framing}

\begin{tabular}{|c|c|c|c|}
\hline $\begin{array}{l}\text { RISK AVERSE } \\
100 \text { homes at risk }\end{array}$ & $\%$ & $\begin{array}{l}\text { RISK SEEKING } \\
100 \text { homes at risk }\end{array}$ & $\%$ \\
\hline (1) Plan guaranteed to save exactly 25 homes. & 65 & $\begin{array}{l}\text { Plan has a } 25 \text { per cent chance of saving } 100 \\
\text { homes and a } 75 \text { per cent chance of saving } \\
\text { zero homes. }\end{array}$ & 35 \\
\hline $\begin{array}{l}\text { (2) Plan guaranteed to result in the destruction of } \\
\text { exactly } 75 \text { homes. }\end{array}$ & 9 & $\begin{array}{l}\text { Plan has a } 75 \text { per cent chance of resulting in } \\
\text { the destruction of } 100 \text { homes and a } 25 \text { per } \\
\text { cent chance of resulting in the destruction of } \\
\text { zero homes. }\end{array}$ & 91 \\
\hline $\begin{array}{l}\text { RISK AVERSE } \\
500 \text { homes at risk }\end{array}$ & $\%$ & $\begin{array}{l}\text { RISK SEEKING } \\
500 \text { homes at risk }\end{array}$ & $\%$ \\
\hline (3) Plan guaranteed to save exactly 125 homes. & 67 & $\begin{array}{l}\text { Plan has a } 25 \text { per cent chance of saving } 500 \\
\text { homes and a } 75 \text { per cent chance of saving } \\
\text { zero homes. }\end{array}$ & 33 \\
\hline $\begin{array}{l}\text { (4) Plan guaranteed to result in the destruction of } \\
\text { exactly } 375 \text { homes. }\end{array}$ & 11 & $\begin{array}{l}\text { Plan has a } 75 \text { per cent chance of resulting in } \\
\text { the destruction of } 500 \text { homes and a } 25 \text { per } \\
\text { cent chance of resulting in the destruction of } \\
\text { zero homes. }\end{array}$ & 89 \\
\hline
\end{tabular}

Notes: the lighter grey cells signify respondents receiving a gain ('save') frame, whereas the darker grey cells signify respondents receiving a loss ('destroy') frame. The numbers in each pair of numbers in the two columns in each section, (a) and (b), sum 100 per cent.

Source: authors. 
action (section (a)) plus the percentage who chose a more risk-seeking action (section (b)). For example, looking at the first row of Table 4, when presented with a flood that threatens Ioo homes and given the choice of implementing a plan 'guaranteed to save exactly 25 homes from being destroyed' or one that offers 'a 25 per cent chance of saving roo homes from being destroyed, and a 75 per cent chance of saving zero homes from being destroyed', 65 per cent of the respondents chose the first plan (row one, section (a)) and the other 35 per cent chose a more risky but potentially more beneficial plan that could potentially save all ioo homes (row one, section (b)).

In both the Ioo- and 500-home situations, around two-thirds of EMs select the sure outcome (a guaranteed saving of 25 or 125 homes out of 100 and 500 homes in section (a), rows one and three, respectively) when the decision context is framed as a gain (homes saved); that is, EMs are averse to gambling with benefits. The remaining one-third seeing the gain frame chose the more risk-seeking alternative, evincing a willingness to gamble with benefits.

The choices appear radically different for those respondents seeing the problem framed as losses. Only roughly one-tenth of respondents in both the Ioo- and 500home situations select the sure outcome (a guaranteed loss of 75 or 375 homes out of 100 and 500 homes in section (a), rows 2 and 4, respectively). The other 90 per cent or so choose the more risk-seeking alternative by gambling to save 75 per cent of the homes from being destroyed against all of the homes being destroyed.

A direct comparison of the respective gain and loss frames (across the rows) yields striking differences in the percentage of respondents selecting risk-averse and riskseeking actions, as illustrated in Table 4 by the different shaped symbols surrounding the percentages. For instance, the circled numbers of 65 and 9 in section (a), rows I and 2 , indicate that 65 per cent of those presented with a gain frame in the Ioohome problem chose the risk-averse option, whereas only 9 per cent of those presented with a loss frame in the Ioo-home problem chose the risk-averse option. The same Somers's D-in this case with two binary variables - can be used to demonstrate a statistically significant difference at less than a o.or level. A Somers' D value of 0.56 in the top half of Table 4 shows that EMs presented with the Ioo-home context and a gain frame are 56 per cent more likely to choose a risk-averse option than those presented with the Ioo-home context and a loss frame. Similarly, the same Somers' D value of 0.56 in the lower half of Table 4 shows that EMs presented with the 500-home context and a gain frame are 56 per cent more likely to choose a riskaverse option than those presented with a loss frame.

Consistent with the caution about avoiding misleading conclusions from the different outcomes in Scenario I, the differences in preferred actions in equivalent situations framed as losses or as gains do not suggest one frame encourages better choices than the other. Rather, the salience of framing suggests that the threat of a loss will weigh more heavily in an emergency management decision than the possibility of an equivalent gain. Stated differently, EMs appear more likely to pursue aggressive, more risky actions to reduce threats when perceived potential losses are involved than when perceived potential gains are at stake. 


\section{Scenario III: omissions and commissions bias among emergency managers}

Neither of the first two scenarios forces EMs to choose between two actions that each could yield a bad outcome, either acting on uncertain information about a forecasted event that may not occur, or not acting on uncertain information about a forecasted event that may occur. The first eventuality may mean incurring unnecessary costs and getting 'nailed to the wall' vis-à-vis public opinion for issuing a false warning (Donner, 2008), while the second may engender damages that could have been lessened. Therefore, the EM respondents were asked in the final scenarios about their attitudes regarding making a choice whether to utilise a long-term forecast that, in hindsight, turns out to be a wrong move. These are referred to here as a 'commission miscalculation' and an 'omission miscalculation', or mis-commit and mis-omit in shorthand. A 'commission miscalculation' refers to choosing to take a costly action in response to a seasonal forecast that indicates an elevated risk of a destructive flood occurring in the next three months, and then not having any such event occur. In contrast, an 'omission miscalculation' refers to making a choice not to take an action in response to such a forecast and then having a destructive flood occur. In both cases, a destructive flood is described as one that would severely damage or destroy infrastructure and a large number of homes and businesses in the county, with full recovery possibly taking at least one year. In addition, it was asserted that a decision to take action in response to the forecast would necessitate considerable effort and the expenditure of a significant amount of the county's annual emergency management budget, and that the actions would need to begin immediately. Several statements were then provided that described possible implications of the mis-commit and mis-omit situations, and the EMs were asked to indicate their level of agreement with each.

Section (a) on the left-hand side of Table 5 shows the results pertaining to one of these statements, specifically the level of agreement with the statement that 'in light of my decision to take action, and because the forecasted flood did not occur, I would feel [ . . . ] about the security of my job $(n=55)$ or in light of my decision to not take action, and because the forecasted flood did occur, I would feel [ . . . ] about the security of my job $(n=62)$ '. Possible response categories in the [brackets] spanned a seven-point Likert scale, with one indicating 'extreme concern' and seven indicating 'extreme confidence'. As Table 5 shows, a far smaller proportion of the group in the mis-commit category (taking an action but the flood does not occur) expressed high (a rating of one to three) concern about job security than the group in the mis-omit category (not taking action but the flood does occur). The differences between the two groups are significantly different statistically at the o.oor level, using the Somers' D test. Here, the -0.65 test statistic value means that those given the mis-commit treatment are 65 per cent more likely to be less concerned that their miscalculation will impact job security than those given the mis-omit treatment. These differences are not inconsistent with the framing effects discussed above, but we cannot tell for sure whether they reflect differences in risk aversion and framing since we did not force equivalency between the expected costs and benefits. 
Table 5. Mis-commit and mis-omit scenarios: job security and action willingness

\begin{tabular}{|l|l|l|l|l|}
\multirow{2}{*}{$\begin{array}{l}\text { Job concern and } \\
\text { action willingness }\end{array}$} & \multicolumn{3}{|c|}{ Job security concerns } & \multicolumn{2}{c|}{ Willingness to take action } \\
\cline { 2 - 6 } & $\begin{array}{l}\text { (i) Mis-commit } \\
\text { scenario }\end{array}$ & $\begin{array}{l}\text { (ii) Mis-omit } \\
\text { scenario }\end{array}$ & $\begin{array}{l}\text { (iii) Willingness } \\
\text { of self to act }\end{array}$ & $\begin{array}{l}\text { (iv) Perceived willingness } \\
\text { of others to act }\end{array}$ \\
\hline 1 & 4 & 27 & 0 & 2 \\
\hline 2 & 5 & 21 & 0 & 10 \\
\hline 3 & 9 & 16 & 18 & 36 \\
\hline 5 & 22 & 21 & 56 & 29 \\
\hline 6 & 15 & 14 & 16 & 14 \\
\hline 7 & 33 & 16 & 11 & 5 \\
\hline
\end{tabular}

Notes: cell entries reflect percentages; columns sum 100 per cent.

Source: authors.

\section{Scenario IV: attribution bias among emergency managers}

The questions about forecast use miscalculations also permit an indirect evaluation of the potential presence of attribution bias among EMs. In particular, a scenario was presented where some EMs were asked to indicate whether the presence of a commission miscalculation would cause them to be less or more willing to use forecasts in the future. Others were asked the same question but with respect to other EMs rather than to themselves. A difference in responses to these formulations might indicate the presence of 'attribution bias', which could suggest potential concerns about the formation of false consensus in decision-making and/or self-serving behaviour that ignores constructive negative feedback. Specifically:

Assume that you decided to take action to reduce the risks associated with a potential flood, and the expected flood did not occur. How do you think this experience would affect your willingness to take action to reduce the risks associated with a similar flood forecast in the future? $(n=55)$

or

Assume that an emergency manager who is unknown to you, and who works in a different county, decided to take action to reduce the risks associated with a potential flood, and the expected flood did not occur. How do you think this experience would affect the manager's willingness to take action to reduce the risks associated with a similar flood forecast in the future? $(n=58)$

Responses ranged from one ('I [They] would be much LESS willing to take action in the future') to seven ('I [They] would be much MORE willing to take action in 
the future'), with four indicating that the 'experience would have no effect on my [their] future decisions'.

Section (b), the right-hand side of Table 5 , shows statistically significant differences (at the 0.00 I level, using the Somers' D test) between the responses of the two groups. A clear majority of EMs reporting their own willingness to use forecasts indicated that the mis-omit experience would have no effect on their willingness to use similar forecast information in the future. Most of the rest indicated that it would make them more willing to use such information. In contrast, nearly one-half of EMs reporting on the willingness of neighbouring EMs to use forecasts in the future, indicated that those EMs would be less willing to do so (a response rate of one, two, or three).

We do not know for sure why this difference in anticipated behaviour appears, but one plausible explanation is the contribution of 'social desirability' bias; that is, the EM survey respondents may be answering questions about their own intended behaviour that will reflect favourably on them (and not have this pressure when responding to questions about the intended behaviour of others). The discrepancy between self and other behaviour may also reflect an elevation of personality in explaining the actions of others. This would be consistent with an attribution bias. However, the differences between the own and other perspective do not appear in the analogous question about an omission miscalculation. The results are not shown here, but nearly all of the EM respondents in both the own and other perspective groups reported an increased willingness to use future forecast information in the wake of a past failure to do so and then having the forecasted flood occur. A solid explanation of this requires further research, but it may reflect a higher risk tolerance when losses are at stake.

\section{Conclusion}

The results of the survey offer evidence regarding the role of forecast uncertainty in motivating EMs to take action. The central expectation motivating the study holds that both shorter- and longer-term forecast information can improve hazard management, and several examples have demonstrated this. The use of longer-term climate forecasts in emergency management in particular remains limited, however, in part because the greater uncertainty inherent to such forecasts and less familiarity with them place an especially large cognitive burden on local emergency decision-making.

The survey results demonstrated consistently a greater aversion to acts of omission-not taking action in response to a forecast indicating a higher than normal likelihood of flooding, and then experiencing the forecasted flooding - than to acts of commission. Furthermore, EMs take different actions in response to forecasts when outcomes are framed as gains than when they are framed as losses, a systematic bias that attention to framing may mitigate. When a decision is framed as a gain, EMs are more likely to prefer a sure outcome. When a decision is framed as a loss, they are more prone to gamble. Neither option is better on its face, but the difference suggests that forecast framing can influence emergency management decision-making. 
In addition, the results related to numeracy challenges - the ability of EMs to process numerical information consistently-reveal that forecast providers should present uncertain information with care. Statistically significant differences were found in the responses of EMs to a question about activating a costly emergency management plan depending on how the forecast likelihood is presented. In particular, forecasts using proportions (O.I and o.9, for instance) made EMs less likely to take action than when presented with identical likelihoods expressed as frequencies (such as $\mathrm{I}$ in Io and 9 in IO). The difference was statistically significant for the lower value comparison ( $\mathrm{I}$ in IO and O.I), perhaps because EMs routinely confront these probabilities. Finally, there is evidence of a potential bias in viewing the actions and motivations of other EMs as compared to those of oneself. When presented with situations where EMs miscalculated and took an expensive action in response to a forecast, only to have the forecasted event not occur, significantly more EMs reported that other EMs would be less likely to take action in response to a similar forecast in the future. In other words, EMs perceived that others in their profession would have the viewpoint 'once bitten, twice shy'. At the very least, the response indicates a difference in how EMs see their own actions and those of others. It suggests that EMs could hesitate to act after preparing for a forecasted event that never happened, but that the selfevaluation cannot be trusted because of social desirability bias, while the evaluation of others appears less subject to this bias.

The broadest lesson is that EMs with substantial experience employ biases and heuristics, just as do members of the general population or the students that many psychologists use in their experiments and surveys. The producers of forecasts should take such cognitive aspects into account when developing products. Borrowing terminology from Marincioni (2007), who has assessed the role of information technology in shaping interaction in local emergency management, technocentric approaches that focus on technical elements of forecasts need to be supplemented by anthropocentric approaches that concentrate on individual-level human capabilities and resources. As a simple example, forecasts can be expressed in multiple ways-frequencies and probabilities, and perhaps in graphical and narrative formats as well-to give EMs multiple angles from which to approach a problem. Selecting one expression of data alone as the most technically ideal way to present information may bias the interpretation, stimulating systematically more risk-averse or more risk-seeking behaviour than other presentation arrangements.

Extrapolating the survey results to more settings requires several qualifications, though. While the findings appear robust across a wide cross-section of the USresponses are from EMs in 29 states, all regions of the country, and rural and nonrural settings - the sample precludes a claim of full representativeness and the ability to develop population-level estimates of behaviour in all contexts. In addition, some of the findings may not apply to other emergency environments with more ephemeral weather-related hazards, such as tornadoes. These may appear too dynamically and unpredictably for forecast information to offer much utility to EMs (Donner, 2008). 
What is more, biases may be exacerbated (or attenuated) by emergency management activities that bring group dynamics into play, such as within emergency management networks (Roberts and Wernstedt, 20I6) or large-scale evacuations in disaster response settings (Hotchkiss, Aguirre, and Best, 20I3). Although the survey experiments discussed here stylistically emphasise individual cognitive processes, group biases probably shape emergency management decisions in important ways on the ground that the questionnaire did not capture.

Notwithstanding these caveats, for both individual and group decisions, the work suggests that EMs would rather be prepared for a disaster, and risk financial and reputational costs and not have it happen, than be caught flatfooted and unprepared. The politics of blame in emergency management may be different in other domains where the results of managerial decisions are less salient. The history of disaster management shows that EMs and their agencies are more likely to be blamed for something that occurs than to be rewarded for mitigating or preventing a disaster that did not happen, largely because the same blame dynamics apply to their political superiors (Roberts, 20I3, pp. 70-I45). While understandable and probably the only politically palatable choice, this built-in risk aversion can stifle the kind of longerterm, learning-rich, 'riskier' policy choices that Matyas and Pelling (2015) assert decision-makers need to consider to generate deeper community resilience.

In the meantime, more data may shed light on what factors cause the judgements of EMs to vary from what utility theory would predict and more effective resilience would demand. Does education or experience improve decisions? Are seasoned EMs more wary of committing acts of omission because of having been stung by criticism in the past? Further research on the decision processes of EMs should also assess the context in which they interpret data and make decisions. Do they read charts and discuss actions alone in their office? At meetings? With peers by social media or telephone? If even experienced EMs are subject to decision biases, then the decision context becomes important.

Structured decision processes involving multiple stakeholders have the potential to mitigate some of these biases and to improve determinations, measured both by satisfaction with the process, and by outcomes. Most research in environmental resource management situations shows how processes that begin by clarifying norms and values and identifying alternatives and trade-offs have led participants to be much happier with their decision outcomes than in cases where they made decisions without such processes (Arvai and Gregory, 2003; Gregory and Long, 2009; Gregory et al., 20I2). In the hazard forecasts context, a more detailed study of actual decision-making by EMs in Oregon reveals that managers who engaged in group decision processes where they clarified goals, developed feasible alternatives, and tied forecasts to specific tasks were able to use seasonal climate forecasts to prepare for floods while most county EMs were not (Roberts and Wernstedt, 20I6). In addition, regular interaction between forecast providers and EMs increased understanding of forecast products and their utility, consistent with work with subsistence farmers that 
suggests that participatory educational sessions in areas with strong seasonal climate signals have helped to decrease the cognitive challenges of interpreting probabilistic information, and increased farmers' use of seasonal forecasts (Patt and Gwata, 2002; Patt, Suarez, and Gwata, 2005).

The presence of decision biases, as psychologists put it, or departures from the utility model, as economists prefer to say, matters for how forecasters communicate prepare for disasters and hazards. The forecast products themselves should present uncertainty in a variety of formats and take into account the ways in which numbers and stories can shape decisions. Finally, beyond the products themselves, forecasters often communicate with government managers and guide their interpretation of forecast information. This interaction furnishes an opportunity to mitigate the impact of decision biases and ensure consideration of multiple perspectives on a problem.

\section{Acknowledgements}

National Science Foundation award number II33024, National Oceanic and Atmos-

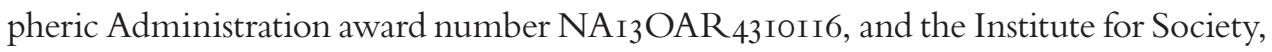
Culture and Environment at Virginia Tech partially supported the work reported here, but this paper represents the authors' views and not necessarily those of these sponsoring entities.

\section{Correspondence}

Kris Wernstedt, School of Public and International Affairs, Virginia Tech, I02 I Prince Street, Alexandria, VA 223I4, United States. Telephone: +I 703706 8I32; fax: + I 703 5I8 8009; e-mail: krisw@vt.edu

\section{Endnotes}

Kris Wernstedt is Visiting Professor at Ardhi University, Tanzania, and Associate Professor at the School of Public and International Affairs, Virginia Tech, United States; Patrick S. Roberts is Associate Professor at the Center for Public Administration and Policy, School of Public and International Affairs, Virginia Tech, United States; and Joseph Arvai is Professor of Sustainable Enterprise at the School for Environment and Sustainability and Ross School of Business, University of Michigan, United States. Kelly Redmond, who passed away on 4 November 20I6, was a Research Professor and Regional Climatologist for the western US, Desert Research Institute, United States.

2 Each of the four scenarios we examine entails four groups of emergency managers, yielding I6 different subgroups of respondents. These subgroups have a similar profile in terms of the respondent characteristics noted in Table I and in the text. This includes the small bias in regional (all I6 subgroups over-represent respondents from the Midwest and under-represent those from the South) and rural settings (all but two over-represent rural counties) found in our overall sample. 


\section{References}

Adams, C.R. and J.H. Golden (2000) 'The tornado problem: forecast, warning, and response'. Natural Hazards Review. I(2). pp. I07-II8.

Arvai, J. and R. Gregory (2003) 'Testing alternative decision approaches for identifying cleanup priorities at contaminated sites'. Environmental Science and Technology. 37(8). pp. I469-I476.

Barnston, A.G. et al. (1994) 'Long-lead seasonal forecasts—where do we stand?'. Bulletin of the American Meteorological Society. 75(II). pp. 2097-2II4.

Changnon, S.A. (I999) 'Impacts of I997-98 El Niño-generated weather in the United States'. Bulletin of the American Meteorological Society. 80(9). pp. I819-I828.

Coventry, W.L. and L.I. Dalgleish (20I5) 'Differences between the single-event and frequency formats of seasonal-climate-forecast probability'. International Journal of Climatology. 35(3). pp. 444-45I.

Demeritt, D. and S. Nobert (2014) 'Models of best practice in flood risk communication and management'. Environmental Hazards. I3(4). pp. 313-328.

Demeritt, D. et al. (2007) 'Ensemble predictions and perceptions of risk, uncertainty, and error in flood forecasting'. Environmental Hazards. 7(2). pp. II5-I27.

Demeritt, D., S. Nobert, H.L. Cloke, and F. Pappenberger (20I3) 'The European flood alert system and the communication, perception, and use of ensemble predictions for operational flood risk management'. Hydrological Processes. 27(I). pp. I47-I57.

Donner, W.R. (2008) 'Decision making as community adaptation: a case study of emergency managers in Oklahoma'. Disasters. 32 (2). pp. 292-302.

Dutton, J.A. (2002) 'Opportunities and priorities in a new era for weather and climate services'. Bulletin of the American Meteorological Society. 83(9). pp. I303-I3I I.

Frick, J. and C. Hegg (20II) 'Can end-users' flood management decision making be improved by information about forecast uncertainty?’. Atmospheric Research. I00 (2), pp. 296-303.

Gigerenzer, G. (1994) 'Why the distinction between single-event probabilities and frequencies is important for psychology (and vice versa)'. In G. Wright and P. Ayton (eds.) Subjective Probability. Wiley, New York, NY. pp. I29-I6I.

Gigerenzer, G. et al. (2005) 'A 30\% chance of rain tomorrow: how does the public understand probabilistic weather forecasts?'. Risk Analysis. 25(3). pp. 623-629.

Gigerenzer, G. and U. Hoffrage (I995) 'How to improve Bayesian reasoning without instruction: frequency formats'. Psychological Review. I02 (4). pp. 684-704.

Gregory, R. et al. (2012) Structured Decision Making: A Practical Guide to Environmental Management Choices. Wiley-Blackwell, Hoboken, NJ.

Gregory, R. and G. Long (2009) 'Using structured decision making to help implement a precautionary approach to endangered species management'. Risk Analysis. 29(4). pp. 5I8-532.

Hapuarachchi, H.A.P., Q.J. Wang, and T.C. Pagano (20II) 'A review of advances in flash flood forecasting'. Hydrological Processes. 25(I8). pp. 277I-2784.

Hartmann, H.C., T.C. Pagano, S. Sorooshian, and R. Bales (2002) 'Confidence builders: evaluating seasonal climate forecasts from user perspectives'. Bulletin of the American Meteorological Society. 83(5). pp. $683-698$.

Hoetmer, G.J. (I99I) 'Introduction'. In T.E. Drabek and G.J. Hoetmer (eds.) Emergency Management: Principles and Practice for Local Government. International City Management Association, Washington, DC. pp. xvii-xxxiv.

Hoss, F. and P. Fischbeck (2015) 'Increasing the value of uncertain weather and river forecasts for emergency managers'. Bulletin of the American Meteorological Society. 97(I). pp. 85-97.

Hotchkiss, H.L., B.E. Aguirre, and E. Best (2013) 'A critique of the official report on the evacuation of the World Trade Center: continued doubts'. Disasters. 37(4). pp. 695-704.

Jensen, J. and G. Youngs (2015) 'Explaining implementation behaviour of the national incident management system (NIMS)'. Disasters. 39(2). pp. 362-388. 
Joslyn, S. and J. LeClerc (2013) 'Decisions with uncertainty: the glass half full'. Current Directions in Psychological Science. 22(4). pp. 308-315.

Joslyn, S.L. and J.E. LeClerc (20I2) 'Uncertainty forecasts improve weather-related decisions and attenuate the effects of forecast error'. Journal of Experimental Psychology-Applied. I8(I). pp. I26-I40.

Joslyn, S.L. and R.M. Nichols (2009) 'Probability or frequency? Expressing forecast uncertainty in public weather forecasts'. Meteorological Applications. I6(3). pp. 309-3I4.

Joslyn, S. and S. Savelli (2010) 'Communicating forecast uncertainty: public perception of weather forecast uncertainty'. Meteorological Applications. I7 (2). pp. I80-I95.

Joslyn, S., L. Nadav-Greenberg, and R.M. Nichols (2009) 'Probability of precipitation: assessment and enhancement of end-user understanding'. Bulletin of the American Meteorological Society. 90(2). pp. I85-I93.

Joslyn, S., S. Savelli, and L. Nadav-Greenberg (20II) 'Reducing probabilistic weather forecasts to the worst-case scenario: anchoring effects'. Journal of Experimental Psychology: Applied. I7(4). pp. 342-353.

Kahneman, D. and A. Tversky (I979) 'Prospect theory: an analysis of decision under risk'. Econometrica. 47(2). pp. 263-29I.

Klein, G.A., J.M. Orasanu, and R. Calderwood (1993) Decision Making in Action: Models and Methods. Ablex, Norwood, NJ.

Kox, T., L. Gerhold, and U. Ulbrich (2015) 'Perception and use of uncertainty in severe weather warnings by emergency services in Germany'. Atmospheric Research. I58-I59 (May). pp. 292-30I.

Lazo, J.K., A. Bostrom, R.E. Morss, J.L. Demuth, and H. Lazrus (20I5) 'Factors affecting hurricane evacuation intentions'. Risk Analysis. 35(เо). pp. I837-I857.

Lazo, J.K., R.E. Morss, and J.L. Demuth (2009) '30o billion served: sources, perceptions, uses, and values of weather forecasts'. Bulletin of the American Meteorological Society. 9o (6). pp. 785-798.

LeClerc, J. (2014) Communicating Weather and Climate Uncertainty: Exploratory Research in Cognitive Psychology. PhD dissertation. https://digital.lib.washington.edu/researchworks/bitstream/handle/ I773/26360/LeClerc_washington_0250E_I3285.pdf?sequence $=$ I \&isAllowed=y (last accessed on 24 April 2018).

LeClerc, J. and S. Joslyn (20I5) 'The cry wolf effect and weather-related decision making'. Risk Analysis. 35(3). pp. 385-395.

Lin, L., C. Rivera, M. Abrahamsson, and H. Tehler (2017) 'Communicating risk in disaster risk management systems-experimental evidence of the perceived usefulness of risk descriptions'. Journal of Risk Research. 20 (I2). pp. I534-I553.

Livezey, R.E. and M.M. Timofeyeva (2008) 'The first decade of long-lead U.S. seasonal forecasts: insights from a skill analysis'. Bulletin of the American Meteorological Society. 89(6). pp. 843-885.

Marincioni, F. (2007) 'Information technologies and the sharing of disaster knowledge: the critical role of professional culture'. Disasters. 3I (4). pp. 459-476.

Matyas, D. and M. Pelling (20I5) 'Positioning resilience for 20I5: the role of resistance, incremental adjustment and transformation in disaster risk management policy'. Disasters. 39(SI). pp. SI-Si8.

Miller, C.H., B.J. Adame, and S.D. Moore (2013) 'Vested interest theory and disaster preparedness'. Disasters. 37(I). pp. I-27.

Millner, A. and R. Washington (20I I) 'What determines perceived value of seasonal climate forecasts? A theoretical analysis'. Global Environmental Change. 2I(I). pp. 209-2I8.

Morss, R.E., J.L. Demuth, and J.K. Lazo (2008) 'Communicating uncertainty in weather forecasts: a survey of the US public'. Weather and Forecasting. 23(5), pp. 974-99I.

Morss, R.E., J.L. Demuth, A. Bostrom, J.K. Lazo, and H. Lazrus (20I5) 'Flash flood risks and warning decisions: a mental models study of forecasters, public officials, and media broadcasters in Boulder, Colorado'. Risk Analysis. 35(II). pp. 2009-2028.

Morss, R.E. and J.L. Demuth (20I6) 'Understanding public hurricane evacuation decisions and responses to forecast and warning messages'. Weather and Forecasting. 3I(2). pp. 395-4I7. 
Murphy, A.H. and R. Winkler (I977) 'Can weather forecasters formulate reliable forecasts of precipitation and temperature?'. National Weather Digest. 2. pp. 2-9.

Murphy, A.H., S. Lichtenstein, B. Fischhoff, and R.L. Winkler (I980) 'Misinterpretations of precipitation probability forecasts'. Bulletin of the American Meteorological Society. 6I (7). pp. 695-70I.

Newson, R. (2002) 'Parameters behind "nonparametric" statistics: Kendall's tau, Somers' D and median differences'. Stata Journal. 2 (I). pp. 45-64.

Nicholls, N. (I999) 'Cognitive illusions, heuristics, and climate prediction'. Bulletin of the American Meteorological Society. 80(7). pp. I385-I397.

Novak, D.R. et al. (2014) 'Precipitation and temperature forecast performance at the Weather Prediction Center'. Weather and Forecasting. 29(3). pp. 489-504.

O'Lenic, E.A., D.A. Unger, M.S. Halpert, and K.S. Pelman (2008) 'Developments in operational long-range climate prediction at CPC'. Weather Forecasting. 23(3). pp. 496-5I5.

Pagano, T.C. et al. (2OI4) 'Challenges of operational river forecasting'. Journal of Hydrometeorology. I5 (4). pp. I692-I707.

Pappenberger, F. et al. (20I3) 'Visualizing probabilistic flood forecast information: expert preferences and perceptions of best practice in uncertainty communication'. Hydrological Processes. 27(I). pp. I32-I46.

Patt, A. and C. Gwata (2002) 'Effective seasonal climate forecast applications: examining constraints for subsistence farmers in Zimbabwe'. Global Environmental Change. I2(3). pp. I85-I95.

Patt, A., P. Suarez, and C. Gwata (2005) 'Effects of seasonal climate forecasts and participatory workshops among subsistence farmers in Zimbabwe'. Proceedings of the National Academy of Sciences of the United States of America. IO2 (35). pp. I2623-I2628.

Peerbolte, S.L. and M.L. Collins (2013) 'Disaster management and the critical thinking skills of local emergency managers: correlations with age, gender, education, and years in occupation'. Disasters. 37 (I). pp. 48-60.

Peters, E. et al. (2006) 'Numeracy and decision making'. Psychological Science. I7(5). pp. 407-4I3.

Pielke, R.A., Jr. and C.N. Landsea (I999) 'La Niña, El Niño, and Atlantic hurricane damages in the United States'. Bulletin of the American Meteorological Society. 80(Io). pp. 2027-2034.

Pielke, R.A., Jr. and R.A. Pielke, Sr. (I997) 'Vulnerability to hurricanes along the U.S. Atlantic and Gulf coasts: considerations of the use of long-term forecasts'. In H.F. Diaz and R.S. Pulwarty (eds.) Hurricanes: Climate and Socioeconomic Impacts. Springer-Verlag, Berlin. pp. I47-I84.

Pulwarty, R.S. and T.S. Melis (200I) 'Climate extremes and adaptive management on the Colorado River: lessons from the I997-I998 ENSO event'. Journal of Environmental Management. 63 (3). pp. 307-324.

Reyna, V.F. and C.J. Brainerd (2008) 'Numeracy, ratio bias, and denominator neglect in judgments of risk and probability'. Learning and Individual Differences. I 8(I). pp. 89-I07.

Roberts, P.S. (2013) Disasters and the American State: How Politicians, Bureaucrats, and the Public Prepare for the Unexpected. Cambridge University Press, New York, NY.

Roberts, P.S. and K. Wernstedt (20I6) 'Using climate forecasts across a state's emergency management network'. Natural Hazards Review. I7(3). https://ascelibrary.org/doi/full/ı..Io6I/\%28ASCE \%29NH.I527-6996.0000222 (last accessed on 24 April 2018).

Scoggins, J.R. and W.W. Vaughan (I97I) 'How some nonmeteorological professionals view meteorology and weather forecasting'. Bulletin of the American Meteorological Society. 52(Io). pp. 974-980.

Silver, A. (2015) 'Watch or warning? Perceptions, preferences, and usage of forecast information by members of the Canadian public'. Meteorological Applications. 22(2). pp. 248-255.

Sink, S.A. (I995) 'Determining the public's understanding of precipitation forecasts: results of a survey'. National Weather Digest. I9. pp. 9-I5.

Slovic, P., J. Monahan, and D.G. MacGregor (2000) 'Violence risk assessment and risk communication: the effects of using actual cases, providing instruction, and employing probability versus frequency formats'. Law and Human Behavior. 24(3). pp. 271-296. 
Sorensen, J.H. and D.S. Mileti (1987) 'Decision-making uncertainties in emergency warning system organizations'. International Journal of Mass Emergencies and Disasters. 5(I). pp. 33-6I.

Stewart, T.R., P.J. Roebber, and L.F. Bosart (I997) 'The importance of the task in analyzing expert judgment'. Organizational Behavior and Human Decision Processes. 69(3). pp. 205-219.

Stokoe, R.M. (20I6) 'Putting people at the centre of tornado warnings: how perception analysis can cut fatalities'. International Journal of Disaster Risk Reduction. I7. pp. I37-I53.

United States Office of Management and Budget (20I0) Federal Register. 75 (I23). 28 June. https:// www.gpo.gov/fdsys/pkg/FR-2010-06-28/pdf/2010-I5605.pdf (last accessed on 4 May 20I8).

Weaver, J. et al. (2013) 'An overview of a demographic study of United States emergency managers'. Bulletin of the American Meteorological Society. 95(2). pp. 199-203.

Werner, K., K. Averyt, and G. Owen (2013) 'River forecast application for water management: oil and water?'. Weather, Climate, and Society. 5(3). pp. 244-253.

Wernstedt, K. and R. Hersh (2002) 'Climate forecasts in flood planning: promise and ambiguity'. Journal of the American Water Resources Association. 38(6). pp. I703-I7I4.

Wernstedt, K. and R. Hersh (2004) 'Climate forecasts and flood planning under the reign of ENSO'. Natural Hazards Review. 5(2). pp. 97-I05.

Zabini, F., V. Grasso, R. Magno, F. Meneguzzo, and B. Gozzini (2015) 'Communication and interpretation of regional weather forecasts: a survey of the Italian public'. Meteorological Applications. $22(3)$. pp. 495-504. 